\title{
Entre Chico Mendes e Quine: uma conversa com Manuela Carneiro da Cunha e Mauro Almeida
}

Between Chico Mendes and Quine: Talking with Manuela Carneiro da Cunha and Mauro Almeida

Joana Cabral de Oliveira

\section{(2) OpenEdition}

\section{Journals}

\section{Edição electrónica}

URL: http://journals.openedition.org/aa/6661

DOI: 10.4000/aa.6661

ISSN: 2357-738X

\section{Editora}

Programa de Pós-Graduação em Antropologia Social (UnB)

Edição impressa

Paginação: 205-220

ISSN: 0102-4302

\section{Refêrencia eletrónica}

Joana Cabral de Oliveira, «Entre Chico Mendes e Quine: uma conversa com Manuela Carneiro da Cunha e Mauro Almeida», Anuário Antropológico [Online], v.45 n.3 | 2020, posto online no dia 16 setembro 2020, consultado o 27 abril 2021. URL: http://journals.openedition.org/aa/6661 ; DOI: https://doi.org/10.4000/aa.6661

\section{cc) (†)}

Anuário Antropológico is licensed under a Creative Commons Atribuição-Uso Não-Comercial-Proibição de realização de Obras Derivadas 4.0 International. 


\title{
entrevista
}

\author{
. $45 \cdot$ n. 3 - setembro-dezembro $\cdot 2 \odot 2 \odot .3$
}


entrevista

Entre Chico Mendes e Quine - uma conversa com Manuela Carneiro da Cunha e Mauro Almeida

Joana Cabral de Oliveira 


\section{Entre Chico Mendes e Quine - uma conversa com Manuela Carneiro da Cunha e Mauro Almeidas}

DOI: https://doi.org/10.4000/aa.6661

\section{Joana Cabral de Oliveira - Universidade Estadual de Campinas - Brasil}

Professora do Departamento de Antropologia da Unicamp. Doutora em Antropologia pela USP, realizou ORCID： $\odot 000-0002-4308-8562$ suas pesquisas junto aos Wajãpi, tendo atuação indigenista junto a esse e outros povos indígenas nas áreas de educação, saúde e questões ambientais. Também realizou pesquisas de antropologia da ciência junto a botânicos e em pesquisa colaborativa sobre leishmaniose.

Manuela Carneiro da Cunha e Mauro Almeida são referências para se pensar o diálogo entre conhecimentos de povos tradicionais e diferentes campos da ciência. Nessa conversa, eles recuperam suas trajetórias e tecem uma narrativa sobre as particularidades da antropologia brasileira na configuração de conexões tranversais entre etnologia e estudos de ciência e tecnologia.
Manuela Carneiro da Cunha and Mauro Almeida are references in the dialogue between traditional ecological knowledge and different fields of science. In this interview, they recover their trajectories and weave a narrative about the particularities of Brazilian anthropology in a configuration of transversal connections between ethnology and science and technology studies. 
Em um esforço para compreender como a etnologia e a antropologia da ciência estabelecem um diálogo muito marcante na antropologia brasileira, propusemos uma entrevista com dois dos autores que entendemos ser pioneiros e mesmo fundadores de um eixo transversal entre tais subáreas de nossa disciplina. Manuela Carneiro da Cunha (professora da Universidade de Chicago e da Universidade de São Paulo) e Mauro Almeida (professor da Universidade Estadual de Campinas) são casados entre si, e a possibilidade de uma conversa conjugada nos pareceu produtiva, nos moldes do que acontece em diversas comunidades tradicionais, onde os saberes do casal se coconstituem em um diálogo produtivo. Ambos trabalham com povos tradicionais e com as ciências em diferentes escopos, o que nos permite traçar uma narrativa possível tanto para a emergência do debate como para passos futuros.

Foi em uma manhã de um fevereiro pré-pandêmico que Joana Cabral de Oliveira foi à casa paulistana do casal. Joana têm participado de diferentes projetos liderados por Manuela, o que dá à entrevista certo tom intimista e possibilitou que o casal de antropólogos pudesse instaurar um diálogo e uma reflexão conjunta a partir de praticamente uma única pergunta.

O que se segue é um esforço reflexivo bastante espontâneo, em que as trajetórias pessoais de cada um divergem, mas conduzem a questões de ciência e etnologia (em sentido amplo), ainda que com inflexões distintas em como cada um atua e pensa sobre esse campo de pesquisa e ação.

Joana: A antropologia brasileira promoveu um certo encontro bastante peculiar entre a etnologia e a antropologia da ciência. Reconhecemos isso sobretudo no trabalho de vocês dois e do Eduardo Viveiros de Castro $^{1}$ ao empreender um esforço de diálogo entre essas duas áreas. Essa percepção faz algum sentido para vocês? Concordam que a antropologia brasileira talvez tenha proporcionado esse encontro que parece não acontecer tanto em outros lugares?

Mauro: Bom, não acho que é só na antropologia brasileira, porque, você vê, na França também há esse movimento: Latour ${ }^{2}$ tem feito essa aproximação. Ainda nessa linha, há uma convergência de estudos de história da ciência que confrontam tradições de conhecimentos de povos que antes eram tidos como não científicos, em comparação com a ciência moderna. Estou falando agora de um grupo que é organizado pela Aparecida Vilaça ${ }^{3}$ e pelo Geoffrey Lloyd ${ }^{4}$, que é especialista de ciência na China e na Grécia Antiga. Começou com um seminário virtual no qual participávamos, Manuela e eu, e fazia essa aproximação da etnologia com a história comparada da ciência, e resultou em um encontro na Universidade de Cambridge.

Manuela: Várias pessoas participaram do encontro, como Marilyn Strathern ${ }^{5}$, mas também helenistas e especialistas da computação. Já houve duas rodadas desses encontros reais em seminário e já saíram os textos resultantes do primeiro encontro na revista HAU. ${ }^{6}$ Mas acho que o Mauro e eu tivemos, digamos, caminhos
$\S$ Entrevista realizada por Joana Cabral de Oliveira, editada por Guilherme Sá, Felipe Sussekind e Joana Cabral de Oliveira e transcrita por Fabiana Nóbrega (bolsista PIBIC/Unicamp), a quem somos gratos.

1 Professor do Museu Nacional da Universidade Federal do Rio de Janeiro, etnólogo e um dos grandes nomes da antropologia brasileira.

2 Bruno Latour, importante autor na fundação dos Estudos de Ciência e Tecnologia (STS), professor do Massachussets Institute of Technology (EUA).

3 Aparecida Vilaça é etnóloga e professora do Museu Nacional/UFRJ.

4 Aparecida Vilaça é etnóloga e professora do Museu Nacional/UFRJ. 
bem diferentes. O Mauro sempre se interessou por matemática, apesar de que quem tinha estudado matemática era eu, mas ele que é o verdadeiro matemático aqui, e você conhece provavelmente o artigo dele sobre Lévi-Strauss ${ }^{7}$, no Current Antropolog $y^{8}$, que é bastante antigo e que justamente está mostrando a importância da matemática e do raciocínio matemático no trabalho da antropologia estrutural. E isso continuou para o Mauro em vários trabalhos, um deles em que ele está particularmente investido é sobre uma matemática das formas do parentesco mas isso, Mauro, você fala sozinho. Agora eu, tive um percurso bem diferente. Primeiro porque não é especificamente através da matemática que eu abordei essa questão da ciência em outras tradições. Há um aspecto político muito importante que motivou o meu interesse e quando eu fui fazer parte da plataforma intergovernamental da biodiversidade e serviços ecossistêmicos - o acrônimo é IPBES ${ }^{9}$ - eu fui porque estava interessada em conhecimentos tradicionais.

Uma série de circunstâncias levam a isso. Essa aliança entre o movimento ambientalista e a questão indígena não é óbvia. No Brasil certamente não é óbvia para todo mundo. É muito mais óbvia no exterior do que entre os ecólogos daqui. A gente continua vendo resistência em relação à questão dos conhecimentos tradicionais. Resistência que inclusive se manifesta há muitos anos na ideia de que, por exemplo, na questão dos princípios ativos, há cientistas naturais ilustres na SBPC que opinam que talvez os índios conheçam atividade biológica de certas plantas ou animais, mas que eles não sabem para que serve de verdade. O que é uma maneira de desmerecer um enorme cabedal de conhecimentos, não só de princípios ativos, mas de processos extraordinariamente complicados. O Mauro tem um exemplo ótimo, que é a história das "formigas zumbis" ${ }^{10}$. Então, nessa questão, há um lado militante, que aparece na minha participação no IPBES.

Houve alguns marcos na minha trajetória recente. Um foi em 2012, quando o Aloísio Mercadante ${ }^{11}$ era ministro da Ciência, Tecnologia e Inovação (MCTI). Fui a Brasília junto com meu amigo Beto Ricardo ${ }^{12}$, que queria também apresentar um outro projeto, independente do meu. O que eu propus para o ministro Aloísio foi o seguinte: o conhecimento indígena e tradicional, dada sua importância, devia ser objeto do Ministério da Ciência, Tecnologia e Inovação, e não simplesmente associado ao Ministério do Meio Ambiente, por conta da contribuição dos povos indígenas à conservação da biodiversidade. Era muito importante esse reconhecimento dos conhecimentos indígenas e tradicionais. Eu propunha a criação de um programa nesse sentido, e ele colocou essa ideia no plano plurianual de 2012, que ia de 2012 a 2016. Essa foi a origem de uma primeira encomenda do MCTI, que transferiu, para tanto, fundos ao CNPq para sua efetivação.

Joana: Que está relacionado ao projeto que você está coordenando agora, o diagnóstico ${ }^{13}$ ?

Manuela: Eu estava pronta, depois desse projeto finalizado, para pendurar as chuteiras, mas algo novo tinha ocorrido. Por indicação do conhecido biólogo da UNICAMP, Carlos Joly ${ }^{14}$, eu comecei em 2016 a participar da IPBES, que é o acrônimo em inglês da Plataforma Intergovernamental da Biodiversidade e Serviços Ecossistêmicos. Dentro da força-tarefa dedicada aos Conhecimentos Indígenas e
5 Antropóloga professora da Universidade de Cambridge.

67 Cf. Hau, v. 9, n. 1, 2019. https://www.haujournal.org/ index.php/hau/issue/view/ hau9.1

7 Claude Lévi-Strauss, uma das principais referências teóricas da história da disciplina, foi professor do Collége de France.

8 ALMEIDA, Mauro W. Barbosa. Symmetry and Entropy: Mathematical Metaphors in the Work of Lévi-Strauss. Current Anthropology, v. 31, n. 4, p. 367-385, 1990.

9 Intergovernamental Panel on Biodiversity and Ecosystem Services. http://www.unesco. org/new/en/natural-sciences/ special-themes/biodiversity/ biodiversity-science-and-policy/ ipbes/

10 Metamorfoses e Fronteiras do natural e do humano, 2012 , Semana de Ciências Sociais da Unicamp. https://mwba. files.wordpress.com/2012/11/ almeida-2012-transformac3a7c3b5es-atravc3a9s-de-fronteiras-conferencia1.pdf

11 Economista e um dos fundadores do PT

12 Carlos Alberto (Beto) Ricardo, antropólogo que atuava no Centro Ecumênico de Documentação e Informação (CEDI), e que mais tarde viria a ser o Instituto Socioambiental (ISA).

13 Diagnóstico povos indígenas e comunidades locais e tradicionais no Brasil: contribuições para a biodiversidade, ameaças e políticas públicas: https://sites.google.com/site/ projetocnpq421752/diagnostico?authuser $=0$ 
de Populações Locais na IPBES, a última palavra é dos governos, certo? Os relatórios que a gente apresentava eram, em última análise, vetados ou aprovados pelo conjunto dos governos participantes da IPBES, já que essa Plataforma é uma coisa intergovernamental. Isso limitava certas coisas. Os Estados Unidos e alguns outros países sempre reclamavam das mesmas coisas. Por exemplo, na questão dos polinizadores, certos venenos que se usavam matavam as abelhas, mas muitos países não queriam proibi-los, então objetavam a algumas recomendações... Alguns governos não queriam que se falasse de certos tipos de agrotóxicos, então havia uma censura final por interesses nacionais... Então, o Joly teve uma ideia muito boa: "vamos fazer uma coisa brasileira e sem governo e vamos ligar isso com a SBPC". Todos nós entramos nessa ideia que deu origem ao BPBES, a Plataforma Brasileira da Biodiversidade e Serviços Ecossistêmicos, só que na hora de fazer, a questão do conhecimento tradicional não tinha espaço suficiente lá, não tinha mesmo, muito menos do que tinha no IPBES. No IPBES houve muito apoio à questão do conhecimento tradicional, muito, e isso repercutiu nos relatórios. Quando chegou nesse BPBES, Joly sugeriu espaço reduzido e concentrado em um só capítulo. Quer dizer, a gente participou, tentou botar o máximo que conseguia, mas foi tudo concentrado no capítulo 2, assim como se fosse uma coisa setorial de menor importância: muito pequeno diante da importância dos conhecimentos tradicionais.

E aí ressurgiu um dinheiro ainda do plano plurianual que já havia sido repassado pelo MCTI ao CNPq, coisa que eu não tinha ficado sabendo. Um funcionário do MCTI, muito legal e empenhado no projeto, foi atrás e conseguiu resgatar esse dinheiro em final de 2017. Depois do empenho dele, e sendo uma encomenda do MCTI, eu não pude dizer que não. Embora eu estivesse realmente cansada para me meter numa coisa tão grande como a gente se meteu, achei que deveria usá-lo para dar o devido lugar às contribuições dos povos indígenas e tradicionais à biodiversidade brasileira e às políticas públicas que as afetavam. Foi por isso que a gente fez esse enorme investimento de trabalho de muita gente, tudo no mesmo estilo do IPBES e do BPBES, trabalho pro bono, sem remuneração. Mas isso deu numa enorme colheita, entendeu, está sendo muito legal.

Qual era a ideia política disso? Nas duas gestões anteriores, o agronegócio tinha aumentado seu poder: Dilma ${ }^{15}$ não favoreceu em nada os povos indígenas e tradicionais, ela cedeu aos agropolíticos; e Temer ${ }^{16}$ ainda mais. Mesmo antes de chegar a essa catástrofe que é o governo Bolsonaro ${ }^{17}$, já estava muito claro que a gente precisava colocar em evidência, para os tomadores de decisão e também para os cientistas naturais brasileiros, a importância desse aporte dos conhecimentos e práticas dos povos indígenas e tradicionais. Então a gente se lançou nisso e ficou um espetáculo. O material que a gente tem é enorme, é enorme, tem mais de 80 pessoas colaborando. E conseguimos o apoio da SBPC. Essa foi minha trajetória. Embora, o interesse da questão do conhecimento tradicional seja mais antiga.

Mauro: A minha trajetória é realmente bem diferente. Mas bom, você tinha perguntado por que teria no Brasil essa convergência ou aproximação entre etnologia, de povos tradicionais indígenas ou não, e a antropologia da ciência. É uma questão interessante, fiquei pensando um pouco. Simplificando muito, essa
14 Carlos Alfredo Joly, professor titular do Departamento de Biologia Vegetal na Unicamp.

15 Dilma Rousseff foi presidente do Brasil de janeiro de 2011 a agosto de 2016.

16 Michel Temer, vice-presidente de Dilma Rousseff que assume após impeachment de agosto de 2016 a dezembro de 2018.

17 Jair Bolsonaro, presidente em exercício no momento, inicia seu mandato em janeiro de 2019. 
etnologia no Brasil me parece ter duas correntes bastantes fortes, às vezes desassociadas e às vezes conectadas. Uma delas é a corrente influenciada por Lévi-Strauss, pelo estruturalismo francês, o que significa uma ênfase no conhecimento, no modo de pensar, na diversidade cultural e também na tese, bastante forte de Lévi-Strauss, de que há uma ciência de povos sem escrita, no sentido forte da palavra. Por isso que a Enciclopédia da Floresta ${ }^{18}$, que é organizada por Manuela e eu, é dedicada a Chico Mendes ${ }^{19}$ e a Lévi-Strauss. Pode parecer estranho, pois Lévi-Strauss não era um ativista, mas é um livro com uma motivação ativista e, ao mesmo tempo, voltado para o conhecimento, pois tem esse peso formativo dessas duas figuras. Nessa corrente da antropologia brasileira estão incluídos o Eduardo Viveiros de Castro e a Manuela, com interesses por sistemas de conhecimento. Acho que no caso do Eduardo, mais pelas implicações filosóficas, e aqui filosofia também no sentido forte, do pensamento ameríndio; e no caso da Manuela, e no meu mesmo, por uma tese que está no primeiro capítulo de "O pensamento selvagem": de que não somente existe um conhecimento indígena muito rico, mas também uma convergência nos resultados da ciência química, que classifica substâncias por uma composição invisível, com os resultados fenomenológicos da ciência do concreto. Por exemplo, a tabela periódica dos elementos dá certas propriedades, e uma ciência do concreto - que é a do cozinheiro, ou a do médico popular ou do indígena - faz uma classificação baseada na percepção, no percepto, e chega aos mesmos resultados classificatórios.

A crítica antropológica a essa tese de Lévi-Strauss, diz: "não, mas isso é uma tentativa de padronizar o conhecimento tradicional recuperando dele apenas aquilo que é mais confirmado pela ciência, como se a ciência fosse o árbitro da qualidade, a calibragem do que presta e do que é mera superstição ou besteira". Essa crítica visa dar um tratamento simétrico a conhecimentos científicos e conhecimentos tradicionais. Contudo, a atitude de Lévi-Strauss e minha tem apoio em uma posição da filosofia da ciência pouco conhecida no Brasil. Vou dar um nome que não é familiar: van Fraassent ${ }^{20}$. É um filósofo holandês radicado nos Estados Unidos, e que defende uma interpretação do empirismo segundo a qual múltiplas teorias podem convergir para os mesmos resultados experimentais.

Enfim, eu estou querendo reconstituir na minha cabeça uma conexão entre essa formação de uma antropologia meio projeto Harvard Brasil Central, e meio criatividade brasileira, que inclui Manuela (com Os Mortos e os Outros) e Eduardo, com o influente artigo sobre pessoa escrito em colaboração com Anthony Seeger e Roberto da Matta ${ }^{21}$. Essa vertente leva à reformulação deleuziana do estruturalismo por Viveiros de Castro, que conserva porém a atenção lévi-straussiana com esquemas de pensamento.

Quanto à influência de Deleuze ${ }^{22}$ - gosto muito dos estudos de Deleuze sobre Kant $^{23}$, Espinoza ${ }^{24}$ e outros. Também vejo com muito interesse o uso que Deleuze e Guattari ${ }^{25}$ fazem de analogias com figuras da ciência - como mitologia contemporânea. Aliás, essa expressão é do Lévi-Strauss, segundo quem a ciência moderna é a mitologia do leigo contemporâneo: você acredita com base na autoridade dos mais velhos, porque é bonita e porque funciona. A mesma coisa que a ciência da
18 CARNEIRO DA CUNHA, Manuela; ALMEIDA, Mauro Barbosa de (Orgs.). Enciclopédia da Floresta: o Alto Juruá: práticas e conhecimentos das populações São Paulo: Cia. das Letras, 2002. $735 \mathrm{p}$.

19 Seringueiro acreano, ativista importante que lutava em defesa da floresta amazônica e de seus povos. Assassinado em 1988.

20 Bastiaan Cornelis van Fraassen, professor de Filosofia na Universidade do Estado de São Francisco, nos Estados Unidos.

21 Anthony Seeger, foi professor no Museu Nacional/UFRJ, e é professor da University of California. Roberto da Matta, professor aposentado na Pontifícia Universidade Católica do Rio de Janeiro (PUC/RJ). Aqui se trata de um referência ao artigo "A construção da pessoa nas sociedades indígenas brasileiras", publicado no Boletim do Museu Nacional, n. 32, maio de 1979. 
floresta e do xamã. Então, há essa tendência especulativa nessa história dessa etnologia brasileira, que tem a ver com Lévi-Strauss e também com Deleuze.

Mas há também outra tendência marcante, que é também reconhecida internacionalmente, que é a de Roberto Cardoso ${ }^{26}$ em seu afastamento do estruturalismo em favor de uma orientação histórica. Quando estive em Cambridge, colegas me perguntavam sobre as últimas novidades do Roberto Cardoso, da fricção interétnica, de Darcy Ribeiro ${ }^{27}$. Na época não caiu a ficha: isto é, o fato de que uma contribuição original da antropologia brasileira era o engajamento na defesa da existência física e cultural de povos atingidos pelo capitalismo e que eram diagnosticados, naquela época, como destinados à destruição. "Povos sem futuro" era um consenso da antropologia engajada dos anos 70, digamos assim. Época em que o Beto Ricardo estava no $\mathrm{CEDI}^{28}$. Nós éramos próximos. Ele iniciava o programa de pesquisa que deu origem ao "Povos Indígenas no Brasil"29, que era na época uma atualização dos Índios e a Civilização do Darcy Ribeiro - um diagnóstico dos efeitos do contato da expansão capitalista sobre povos indígenas, baseado nos arquivos do Serviço de Proteção aos Índios (SPI ${ }^{30}$, com a seguinte originalidade analítica: a distinção dos efeitos do impacto conforme a natureza da frente econômica (agrícola, pecuária, mineradora e extrativista). Esse foi o programa inicial que Beto Ricardo retomou (marcado por artigo pioneiro assinado também por Carlos Alberto Dória ${ }^{31}$ ), e que hoje é continuado no ISA (Instituto Socioambiental) sob a direção de Fanny Ricardo ${ }^{32}$, socióloga pouco conhecida que é contudo uma das mais importantes figuras da etnologia brasileira. A originalidade de Darcy Ribeira era explicar a intensidade da destruição de povos indígenas conforme o tipo de economia representado por diferentes frentes capitalistas ${ }^{33}$. Era ao mesmo tempo uma explicação para as variantes da destruição dos povos indígenas em diferentes regiões do país, associando essas variantes às modalidades do capitalismo: agrícola-exportador, extrativo-minerador, pecuário-comercial, extrativo-exportador. A ideia inovadora é que o efeito de fronteira entre sociedade nacional e povos indígenas era explicado pelo ímpeto econômico da economia invasora, por sua vez explicado pela natureza da atividade. Darcy Ribeiro associou assim os efeitos da expansão capitalista na fronteira - o ritmo, a intensidade a duração da destruição de povos indígenas - com o caráter da economia capitalista. $\mathrm{O}$ diagnóstico que ele fez da ocupação extrativista no Acre, com base nos relatórios do SPI, foi brutal: a frente capitalista mais destrutiva, mais violenta e mais rápida, levando ao extermínio dos povos indígenas que habitavam os últimos formadores da margem direita do Solimões-Amazonas, a saber, os rios Javari, Purus e Juruá. Isso fazia sentido porque as cabeceiras do Purus e do Juruá eram as últimas e mais produtivas fronteiras para a produção de látex de alta qualidade, levando a um processo especulativo o qual se tratava de ir até lá, botar uma placa, voltar a Manaus, e vender a posse.

A despeito do epitáfio formulado por Darcy Ribeiro com base nos relatórios do SPI, o fato é que povos indígenas do Acre sobreviveram. Era um falso diagnóstico. Ainda assim essa tendência refletia, expressava, uma tradição forte na etnologia brasileira. No Museu Nacional há representantes das duas. O Eduardo (Viveiros
22 Giles Deleuze, filósofo francês, lecionou em diferentes universidades da França, entre elas na Universidade de Paris, Sorbonne.

23 Immanuel Kant, filósofo prussiano do século XVIII.

24 Baruch de Espinoza, filósofo do século XVII.

25 Felix Guattari, filósofo e psicanalista francês, que escreveu em parceria com Gilles Deleuze.

26 Roberto Cardoso de Oliveira, um dos fundadores de uma antropologia brasileira, passou por diversas instituições, entre elas o Serviço de Proteção ao Índio, terminando a carreira como professor na Universidade de Brasília. Participou da criação dos programas de pós-graduação em antropologia do Museu Nacional, Universidade de Brasília e de Ciências Sociais da Unicamp.

27 Darcy Ribeiro, antropólogo, participou da fundação de Universidades públicas, foi Ministro da Educação, entre outros cargos políticos nos quais atuou em diferentes instituições relacionadas à pesquisa e defesa dos povos indígenas.

28 Centro de Ecumênico de Documentação e Informação

29 Projeto de caráter enciclopédico e da situação de povos indígenas no Brasil: https://pib.socioambiental.org/ pt/Página_principal

30 Órgão do governo federal que antecedeu a Fundação Nacional do Índio (FUNAI).

31 Sociólogo pela Unicamp, especialista em alimentação.

32 Fanny Ricardo, uma das fundadores do ISA, onde continua trabalhando. 
de Castro), de um lado, com foco no patrimônio intelectual e filosófico dos povos indígenas, em que os pensamentos desses povos poderiam, digamos, ser ensinados ao lado de Espinoza e de outros filósofos. Eu não vejo o Eduardo (Viveiros de Castro) tratar da relação disso com ciência, no sentido usual da palavra...

Joana - Então você não colocaria a filosofia dentro da ciência?

Mauro - Penso que a filosofia até faz parte da ciência sim. Faz parte. Mas há uma separação feita por exemplo por Deleuze, que afirma em seu último livro em colaboração com Guattari, no qual afirma que ciência produz "funções" e filosofia produz "conceitos". A meu ver, há cientistas que são grandes filósofos. Mas vejo a ponte contrastiva que Eduardo estabelece entre a filosofia ocidental e a filosofia ameríndia como uma dignificação do pensamento indígena das Américas, análogo ao que Evans-Pritchard ${ }^{34}$ fez no livro Nuer Religion, um grande livro, que eu aconselhava a meus alunos. Eu indicava esse livro no contexto de discussões sobre revoluções científicas, já que Nuer Religion se distingue radicalmente do livro do mesmo Evans-Pritchard sobre a bruxaria azande ${ }^{35}$. No livro sobre "bruxaria”, conhecimentos e práticas Azande não têm valor cognitivo ou ético: têm uma função utilitária, sociológica, de resolver conflitos sociais. Mas em Nuer Religion, Evans-Pritchard apresenta um sistema metafísico africano análogo ao da teologia católica. Claramente há uma influência da conversão de Evans-Pritchard ao catolicismo - minoria religiosa na Inglaterra.

Você pode fazer uma leitura do Nuer Religion pensando nisso e você vai ver como o panteão de espíritos Nuer é análogo ao panteão politeísta de santos do catolicismo como intermediários face a Deus: entes intermediários entre o céu e a terra que fazem a mediação para uma divindade mais abstrata e vertical. Trata-se de um pensamento metafísico, no sentido filosófico na tradição de São Tomás de Aquino. Evans-Pritchard tem essa coisa muito interessante, a meu ver, de valorização do pensamento especulativo e teológico desses povos, uma valorização dessa capacidade de reflexão epistemológica sobre o que que é o sujeito, o que é objeto, a noção de humanidade. Concordo plenamente com Evans-Pritchard, que compara o pensamento de povos africanos com grandes tradições do pensamento como o Platonismo e o Averroismo. Averróis ${ }^{36}$, um filósofo importante da Idade Média, dizia que há vários níveis de percepção e de acesso ao real: um deles é o dos fantasmas, que você pensa vê, mas que são aparências desveladas quando você tem acesso à existência - e quando isso acontece, é como se baixasse um santo-da-verdade em você, que se converte então em sujeito universal do conhecimento verdadeiro. É uma forma de pensamento que parece muito o pensamento indígena Kaxinawá ${ }^{37}$.

Manuela - Poderia falar mais sobre isso?

Mauro - É a noção que a realidade habitual é uma aparência sob a qual se escondem essências de coisas, que você pode acessar pela experiência xamânica. Mas trata-se de uma experiência de laboratório, que lembra muito a linguagem de físicos, porque aqui o instrumento de laboratório é teu corpo preparado. Tem uma introdução que fiz para um livro de uma aluna minha ${ }^{38}$, em que dou esta bicada no perspectivismo dizendo que é uma condição necessária para esse acesso a um
33 Nota do entrevistado: "Há aqui um paralelo com a Formação Econômica do Brasil de Celso Furtado, surgida na mesma época. Enquanto Darcy Ribeiro visava mostrar os efeitos de diferentes ciclos econômicos sobre povos indígenas, Celso Furtado preocupava-se em mostrar os efeitos desses mesmos ciclos econômicos para a acumulação capitalista. 0 que Darcy Ribeiro caracterizou como efeito frente com efeito máximo de aniquilação de povos locais - o extrativismo amazônico da borracha - Celso Furtado caracterizou como imenso desperdício de mão de obra nordestina emigrada para a Amazônia, porque os lucros resultantes desse movimento não foram reinvestidos na industrialização.

34 Edward Evan Evans-Pritchard foi um antropólogo inglês, que teve um papel fundante na antropologia social, lecionou na Universidade de Oxford na Inglaterra.

35 Bruxaria, oráculos e magia entre os Azande, publicado orginalmente em 1937.

36 Abu Alualide Maomé ibne Amade ibne Maomé ibne Ruxide, filósofo mouro do século XII.

37 Grupo indígena de língua Pano, habita na fronteira brasileiro-peruana na Amazônia ocidental. Se autodenominam Huni-Kuin.

38 LABATE, Beatriz Cauby. O uso ritual da Ayahuasca. São Paulo: Mercado das Letras, 2002. 
mundo que você chega pelo sonho, ou depois da morte ou então num experimento xamânico - é um instrumento, um corpo preparado, uma superfície através da qual fluem substâncias e o corpo também preparado pelo exercício pelo tabaco, ayahuasca e outras substâncias. Há um lado laboratorial para o acesso a outras realidades e a outros sujeitos. $\mathrm{E}$ aí você tem um encontro de repente com a tecnologia e com a filosofia metafísica e com a ciência, porque o cientista também tem esta ideia de acessar o que é invisível a olho nu, usando instrumentos.

Bom, retomando a questão da trajetória, tem uma introdução a um livro da Bia Labate ${ }^{39}$ onde eu também falo da minha própria experiência, o único lugar em que eu falo da minha experiência de uso do ayahuasca. Eu falo de uma anarquia antológica/ontológica, e antológica/antalógica, a lógica da anta. Falo de uma coexistência de regimes ontológicos, não só na mesma sociedade, como a nossa, dentro da ciência, ciência física e matemática em particular, como na mesma pessoa. Eu sempre dou exemplo, que é real, de um cara que de manhã faz física no INPE, satélite e tal, então isso é física newtoniana; à tarde, ele tem que se comunicar com o satélite, e aí entra a teoria da relatividade para ajustar os relógios da terra e do satélite; e no final do dia entra a física quântica pra fazer os aparelhozinhos funcionarem. À noite, esse cientista pratica alquimia. Isso tudo é real.

Joana - O personagem é real?

Mauro - É um personagem real, que não posso identificar, sendo hoje aposentado. Mas há um precedente: Newton passou a maior parte de sua vida praticando Alquimia e cronologia bíblica pra calcular com exatidão a idade do mundo desde que foi criado por Deus.

Você sabe: o Deus de Newton dá corda no sistema do mundo solar, porque nem Newton ${ }^{40}$ e nem ninguém até hoje resolveu uma equação determinista do sistema solar como um todo, e Newton sabia portanto que não há segurança sobre a estabilidade do sistema solar. Newton, grande teórico e calculador, não tinha meios para provar que mesmo um sistema consistente de três corpos - Sol, Terra, Lua - seria estável ao longo de tempos estelares. O grande matemático Poincaré ${ }^{41}$ concorreu a um prêmio oferecido a quem provasse a estabilidade de um sistema de três corpos. Poincaré mandou a suposta prova e ganhou o prêmio - só que não, antes da publicação, Poincaré releu e percebeu que estava errado, porque o que ele tinha provado é que o problema não tem solução. Não se sabe até hoje se o sistema solar é estável, porque permite trajetórias que hoje são chamadas de caóticas. Isso levou à Teoria de Sistemas Dinâmicos: que podem ser determinísticos ou caóticos, ou imprevisíveis. Então comecei a falar demais, quase uma aula... Mas tem essa tendência intelectual, uma tendência intelectualista (realista) e uma tendência ativista (empirista), e as duas podem conviver na mesma pessoa, quer dizer, conflitos ontológicos existem dentro de uma disciplina. Mas esse tipo de conflito pode ser admitido - num regime de anarquia, onde é a pluralidade de visões de mundos. Manuela é um exemplo, ao mesmo tempo portadora de um pensamento estruturalista, mas um estruturalismo já meio anarquizado por uma influência da psicologia histórica de Jean-Pierre Vernant ${ }^{42}$, e, ao mesmo tempo,
39 Beatriz Cauby Labate, doutora em antropologia pela Unicamp, é membro de diversas redes nacional e internacional sobre estudos de psicoativos.

40 Isaac Newton, astrônomo, alquimista e filósofo, fundador da mecânica clássica no final do século XVII.

41 Jules Henri Poincaré, matemático e filósofo da ciência na virada do século XIX para o XX, professor da Universidade de Paris.

42 Historiador especialista em Grécia antiga, professor do Collége de France. 
vetor de uma corrente de antropologia histórica e do indigenismo que converge com tradições do Museu Nacional.

Então são vertentes da etnologia do Brasil agora. A defesa de territórios indígenas e tradicionais associa-se, nos anos de1990, a uma preocupação mundial com a biodiversidade, com a mudança climática, com as questões da ciência, da ecologia e da biologia, porque os povos indígenas estão ocupando, junto com outros povos tradicionais, os territórios mais ricos e remanescentes de biodiversidade no Brasil e no mundo. De repente você tem que ter, queira ou não queira, uma colaboração com esses cientistas da natureza, e com a tecnologia de observação no espaço. A Manuela passou por isso e eu também me envolvi em trabalhos de colaboração com biólogos e geocientistas por causa da necessidade de dar uma fundamentação científica - para justificar a criação das primeiras reservas extrativistas, com base em laudos científicos. Cientistas de qualidade internacional, que atestassem, junto com outras evidências, a importância, de um ponto de vista de um patrimônio nacional, de assegurar que essas áreas permanecessem fora da invasão do capitalismo predatório. Tenho uma dívida muito grande, já cansei de repetir, com Rosa Luxemburgo ${ }^{43}$, que escreveu sobre o ciclo da borracha na Amazônia em A acumulação do capital, que trata da destruição da natureza e da destruição dos povos cuja vida social não é capitalista.

Descobri que cientistas naturais, como Foster Brown ${ }^{44}$ e a Laure Empeirare ${ }^{45}$, têm a capacidade, atribuída a antropólogos, de se comunicar com qualquer pessoa de uma maneira simples, mas correta e profunda. $O$ ignorante era aquele técnico do Ibama que dizia que o seringueiro não pode fazer plano de uso porque não sabe o que é regressão matemática. $O$ técnico não saberia explicar a fórmula que decorou, mas a utilizava para justificar o poder dele e a autoridade e a opressão que ele exerce sobre pessoas que ele trata como ignorantes. Ele é o verdadeiro ignorante, né? Pessoas como o Foster Brown mostravam para mim como seringueiros sem nenhuma educação formal aprendiam melhor princípios de ecologia do que alunos de mestrado. Isso pra mim era uma lição de antropologia, de etnologia, muito grande.

Mas há também uma antropologia da ciência por meio de outras beiradas. Tem pouco no Brasil, eu acho, relativamente, antropologia da ciência de laboratório, como tem pouca antropologia das elites, tal como fazem Catarina Morawska ${ }^{46}$, Natacha Leal ${ }^{47}$, Caio Pompeia ${ }^{48} . .$. E tem também o Stelio Marras ${ }^{49}$, é outra figura dentro deste quadro porque ele fez o estudo da antropologia da ciência com a biologia na USP.

Outro grupo interessante é aquele da UFSCar, do Gabriel Coutinho ${ }^{50}$. Eles trabalham com os pescadores, com algo fascinante que é como os pescadores em jangada determinam o local submerso onde tem lagosta, a uma boa distância da costa, mas com a visibilidade da costa. É um método que os gregos usavam, que é usando a paralaxe, ponto de observação na terra e coisas assim desse tipo, que não é só conhecimento indígena.

Joana - E como você situa a dimensão ontológica com a discussão a propósito de uma antropologia da ciência?
43 Filósofa e economista marxista da passagem do século XIX ao XX.

44 Professor da Universidade Federal do Acre e do Woods Hole Research Center, concentra pesquisas nas áreas de geoquímica e ecologia.

45 Pesquisadora do Institut de Recherche pour le Développement (IRD), botânica que concentra pesquisas na área de agrobiodiversidade de povos tradicionais.

46 Anna Catarina Morawaska Vianna, professora do Departamento de Antropologia da Universidade Federal de São Carlos.

47 Natacha Simei Leal, professora de Antropologia da Universidade do Vale do São Francisco.

48 Pós-doutorando no Departamento de Antropologia da USP. 
Mauro - Quine ${ }^{51}$ é filósofo e lógico importante, e ele é quem argumenta a necessidade de ontologias na matemática e nas ciências. Quine foi professor na Escola Livre de Sociologia, onde lecionei na década de 1970, onde ele lecionou concomitantemente com Radcliffe-Brown ${ }^{52}$ e outros luminares, resultando em seu primeiro livro, publicado em português - O sentido da nova lógica. No seu livro sobre a Relatividade ontológica e outros ensaios, inclui notas de rodapé com exemplos de terminologia de parentesco atribuídas a Raymond Firth ${ }^{53}$. Nesses exemplos, trata-se da indeterminação da tradução. Indeterminação da tradução é o seguinte: você tem um sistema de conhecimento e você vai traduzi-lo para outro. Mas há várias traduções possíveis. A virada pragmática diz o seguinte: as várias traduções são igualmente válidas (ontologicamente) desde que levem aos mesmos efeitos pragmáticos. Chamo esse efeito de acordo pragmático entre ontologias díspares. Quine dá um exemplo famosíssimo da indeterminação da tradução. A antropóloga quer saber qual é o significado da palavra gavagai. Ela registra no seu caderninho o comportamento do informante nativo, que afirma gavagai quando a antropóloga vê um coelho. Mas Quine pergunta: - Quem disse, cara pálida, que isso que foi apontado é o coelho de sua vã ontologia? Pois a palavra, associada ao estímulo, pode referir-se a um pedaço do coelho, ou a um movimento do coelho, ou ao fluxo temporal-coelhal, à uma coelhidão - coelhitude - ou à emergência momentânea da coelhidade? Não há como saber, e essa é a tese da indeterminação ontológica na linguagem.

Heiddeger ${ }^{54}$ dizia que o acesso ao mundo começa com o nível pré-ontológico. Quando o cientista entra no laboratório e pega a maçaneta, esta é um treco que dá acesso a objetos - não é ainda objeto de uma ontologia, mas pretende ao domínio pré-ontológico de pragmata. Treco serve para alguma ação - é pragma, coisa, instrumento. No dicionário de grego e de alemão, está: lá, de fato, em alemão zeug é sufixo - é partícula transitiva, que ganha sentido com Spielzeug (um treco para brincar), Flugzeug (treco pra voar), e assim por diante. Xzeug é um troço que serve para alguma coisa. Heidegger se interessa por zeug porque não é um palavra filosófica, é uma palavra comum: treco seria um "trem” em Minas, indicando coisa qualquer que serve para encontrar entes.

Você vai ao dicionário e vê que não se trata de palavra filosófica, e sim de palavra que designa tanto "coisa qualquer" (pedaço de pano), como negócio, business. Então pragma (singular) e pragmata (plural) apontam para uma ação "prática" ou "pragmática" no sentido atual, mas também a entes comuns e de baixa qualidade: pano, por exemplo. Já encontro pragmático refere-se a Heidegger, que se refere à experiência por meio de instrumentos. Esses instrumentos - evitando um círculo vicioso - não pressupõem ainda uma ontologia: trata-se então de encontros pré-ontológicos.

Então o céu está caindo, mas isso se refere a um fenômeno da experiência. Mudança no regime das águas, caos nos passarinhos, que não sabem mais indicar a sazonalidade, e assim por diante. E o lado do teórico é o globo terrestre... Mas o encontro deles se dá na base da experiência, e não ao ficar convencendo o outro de que tudo isso é aquecimento global, porque isso não tem muito sentido. Mesmo
49 Stelio Alessandro Marras, professor do Instituto de Estudos Brasileiros/USP.

50 Gabriel Coutinho Barbosa, professor do Departamento de Antropologia da Universidade Federal de Santa Catarina.

51 Willard Van Orman Quine, matemático e filósofo norte-americano.

52 Alfred Radcliffe-Brown antropólogo britânico, lecionou na Universidade de Cambridge e é um dos fundadores da antropologia social.

53 Antropólogo da London School of Economics, considerado um dos fundadores da antropologia econômica britânica.

54 Martin Heidegger, filósofo alemão, lecionou na Universidade de Friburgo. 
no ponto de vista da ciência, isso é um rótulo para um conjunto de fenômenos e de modelos, que se dão conectados por experiência com milhares de pontos de observação espaciais e na terra, de sensores de água, sensores nos Polos. E esses indicadores combinados num modelo dão conta dos fenômenos, assim como a teoria, ou melhor uma das teorias dos Ashaninka, porque eles também têm vários mundos. Tem os Ashaninkas jovens que explicam o aquecimento pelas queimadas, crescimento das cidades e tal, mas tem os velhos, que é o Inca que está se aproximando, o sol está se aproximando da Terra, por isso que está cada vez mais quente. Assim como os nordestinos que eu estudei também, o fim do mundo está chegando, e a queimada, e de repente tem o El Niño, tem isso e tem os efeitos sociais da desertificação como consequência da agricultura mais intensiva... A mesma experiência permite um diálogo e uma cooperação e nada impede, pelo contrário, que ela seja explicada por modelo e por mundos da experiência diferentes. Ah, mas aí não vai para escola? Vai, transita. Mas eu parei...

Manuela - Não, continua, eu estou gostando muito.

Mauro - Eu estou fazendo uma série de fios para dizer que há uma trajetória filosófica para essas questões, mas tem uma trajetória de uma filosofia que eu disse que é pouco conhecida da ciência, como o Quine.

Joana - Você está falando de uma filosofia da ciência mais amparada na matemática, pelo que eu estou entendendo...

Mauro - A minha visão pessoal é escorada na matemática, mas esta filosofia da ciência foi despertada e estimulada pela física quântica. Como eu não tenho a matemática suficiente para a física quântica, eu fico numa matemática, digamos, do começo do século, que deu origem a uma explosão dos fundamentos da matemática, crise dos fundamentos... O ponto de partida de Bertrand Russel1 ${ }^{55} \mathrm{e}$ de Frege ${ }^{56}$ é que a lógica seria uma base segura para a matemática, visão exposta no grande livro intitulado Principia Mathematica, que já utilizei como exemplo da relação entre a teoria de linhagem da aristocracia britânica à qual Russell pertencia e sua teoria matemática das relações. É difícil ler esse fato no livro Principa Mathematica, mas entendi o espírito da coisa na prova final do curso com Luiz Henrique Lopes do Santos ${ }^{57}$, em que usei uma página inteira manuscrita para provar que $2+$ $2=4$, para ser aprovado no curso de lógica matemática. Bertrand Russell expõe a visão, continuada por Wittgenstein ${ }^{58}$, de que ciência é lógica combinada a observação empírica. Isso foi em 1914, mas essa visão foi completamente estourada na década de 1930, com a demonstração de que a lógica é incompleta para dar conta do que pode ser provado, e para dar conta do que é verdadeiro.

Outra crise resultou da física quântica, que, de repente, no meio da década de 1920, foi tipificada em um artigo de Heisenberg ${ }^{59}$. Isso porque, segundo os primeiros resultados de Schrödinger ${ }^{60}$ e de Heisenberg, não haveria objetos e trajetórias, e sim ondas e probabilidades de ocorrência. Mas experimentos físicos permitiam observar a trajetória de elétrons - como traços. Mas a teoria quântica diz que não existe um objeto elétron, e sim uma onda que se espalha pelo espaço inteiro. A explicação de Heisenberg é: toda vez que você usa um aparelho de medida, a onda assume o caráter de objeto. O que vemos como trajetória de um objeto - elétron - é
55 Filósofo, lógico e matemático do Reino Unido, ganhou o Nobel de literatura em 1950

56 Gottlob Frege, matemático, filósofo e lógico alemão da virada do século XIX para o XX.

57 Professor do departamento de Filosofia da USP.

58 Ludwing Wittgenstein, filósofo austríaco.

59 Werner Karl Heisenberg, físico alemão, ganhou o Nobel de física em 1932. Estabeleceu as bases da mecânica quântica, famoso pelo "princípio da incerteza".

60 Erwin Rudolf Josef Alexander Schrödinger, físico austríaco. 
de fato a sequência de colapsos de onda com eventos de medida - como a impressão de movimento produzida por imagens fotográficas sucessivas, cada uma das quais registrando um evento individual em um instante do tempo, mas jamais um movimento. Não vemos na câmara de bolas uma partícula em movimento, e sim uma sucessão de encontros pragmáticos.

Há um manual de física para filósofos feito por um físico, que trata de experimentos de física quântica. No final do primeiro volume há exercícios que incluem perguntas do tipo: quando você está olhando uma árvore e você vira de costas, a árvore ainda está lá? Trata-se de avaliar a atitude ontológica e epistemológica de estudantes. Físicos são pluralistas. Já biólogos são dogmáticos, no sentido realista científico, em parte em reação ao criacionismo. Biólogos são superfechados a essa confusão ontológica, com medo disso gerar o criacionismo, da coisa da religião... Então são muito militantes em favor de uma forma de realismo científico que diz o seguinte: o real é o que a ciência biológica diz que é o real.

Joana - Você acha que a biologia não opera com a multiplicidade ontológica?

Mauro - Não opera. Há uma disciplina ontológica na biologia que é a taxonomia, ou classificação. Taxonomias biológicas são ontologias, mas essas ontologias biológicas não divergem quanto ao fundamento evolucionista.

Joana - Mas a taxonomia biológica tende a um sistema global?! Ainda que tenham divergências e disputas internas à taxonomia, ela tem um esforço de ser universal?

Mauro - Sim. Falando como leigo, no plano de espécies já há muita divergência. No campo da paleontologia humana, que trata da taxonomia de ramos que levam à espécie humana, o quadro me parece bastante caótico. Quando saímos do nível da espécie (H. Sapiens, H. Neandertalensis) para o nível ontológico de gênero e de família, tudo fica muito mais subjetivo. Há a corrente apoiada na genética, e há os que se apoiam na morfologia para classificar.

Darwin $^{61}$, que tem sugestões que parecem malucas hoje em dia. Darwin propôs duas teorias interessantes. Interessantes e heterodoxas do ponto de vista da biologia evolucionista atual. A teoria da seleção sexual, e teoria da seleção de grupo. A primeira teoria, a da seleção sexual, diz que fêmeas têm preferências estéticas por machos com maior desempenho visual - expresso em plumagens, cantos e bailados, comportamentos que não são indicativos de aptidão para a sobrevivência ou reprodução.

Dizem que o Darwin ficava deprimido quando via um pavão, e entendi a mensagem quando recentemente vi um pavão arrastando sua imensa cauda. Mais da metade do livro de Darwin sobre a origem do homem trata de evidenciar a existência da seleção sexual em vários níveis da vida. A razão é a que, na última parte do livro, Darwin recorre à seleção sexual para explicar as diferenças entre raças humanas. Segundo Darwin, a explicação nada tem a ver com efeitos do sol ou de doenças, e sim de preferências estéticas.

Quando se trata da relação entre não humanos e humanos, Darwin, em vez de degradar o humano ao animal - como na sociobiologia -, faz o movimento contrário: reconhece todas as qualidades humanas, sem exceção, no nível animal,
61 Charles Darwin, naturalista britânico autor da Teoria da Evolução.

62 Lewis Henry Morgan, antropólogo do século XIX, um dos fundadores da antropologia. 
como atributos de animais não humanos, tais como sentimentos e intelecto. Sob esse ponto de vista, Darwin e o pensamento ameríndio são confluentes. É grotesco achar que a inexistência de fronteira ontológica entre animal e humano é descoberta recente do século XX, quando Darwin, Morgan $^{62}$ e outros exibiram de forma explícita essa posição antiantropocêntrica em que animais não humanos possuem inteligência, memória, previsão do futuro...

Joana - Atualmente se fala também sobre memória de plantas...

Mauro - Sim, plantas têm sistemas de conhecimento distribuído. Manuela, se embarcar nisso, vai adorar! Acabei de comprar um livro sobre comportamento social de polvos. Não somente eles são inteligentes para testes de labirinto como os macacos, no mesmo nível de animais que são considerados como muito avançados, como têm também uma vida social superinteressante. Darwin e Lévi-Strauss estão no mesmo barco. Menos de cem anos depois do livro do Darwin intitulado The variation of animals and plants under domestication em 1868, Lévi-Strauss publica O pensamento selvagem em 1962, reafirmando a autoria de povos neolíticos na domesticação de animais e vegetais. As analogias são flagrantes, entre as quais a observação de que a orientação seletiva de espécies animais não é exclusivamente utilitária, mas obedece a critérios estéticos. Assim, Darwin usa uma página para mostrar exemplos de seleção artificial em gado para traços utilitariamente inúteis: para apresentar o gado na operação de comprar a noiva, o gado precisa ser malhado de tal maneira, tem que ter um chifre de tal jeito, tem que ter não sei que idade... Por quê? É moda, diz Darwin, por analogia com a moda inglesa.

Joana - Tentando juntar as duas falas, Mauro trouxe um olhar sobre certos campos da ciência que dialogam muito com o pensamento de povos tradicionais, justamente porque são ramos da ciência que operam com uma noção de multiplicidade ontológica. Afinal, quando a gente olha os regimes de conhecimento desses povos, vemos que eles não estão trabalhando com uma noção de verdade unívoca. Bom, a trajetória de vocês está muito marcada por uma antropologia brasileira que é engajada, como você mesmo frisou, e que lida com problemas políticos. Me parece que vocês foram jogados nessa temática muito pelo contexto acreano, né?! As questões políticas que estavam acontecendo no Acre estavam relacionadas à questão dos territórios, à necessidade de um diálogo entre seringueiros, indígenas e cientistas para tentar garantir e defender certa territorialidade etc. Uma questão que me parece central é como a política opera nesse jogo, porque a política parece ter a necessidade de estabilidade. Então, se Mauro está mostrando que certos ramos da ciência trabalham com uma multiplicidade ontológica, a política parece ter muita dificuldade em lidar com isso. Como é possível fazer essa negociação no âmbito político, sobretudo essa aliança entre conservação ambiental e povos tradicionais, sem cair numa certa ciência positivista, nisso que Mauro chamou de realismo científico.

Mauro - Vamos falar com a Manuela então.

Manuela - (risos) Você está jogando a bola para mim... É, eu acho eu sou muito mais pragmática no sentido do James ${ }^{63}$. Nessa última empreitada, que é a do diagnóstico ${ }^{64}$, de que você está participando, claramente o objetivo é o interlocutor, é o
63 William James, filósofo norte-americano do final do século XIX. 
tomador de decisão. É para ele que está sendo feito isso, então tem todo um lado de convencimento que, sim, você tem toda razão, precisa afirmar uma série de coisas e não entrar nos pressupostos. A ideia é mostrar os efeitos destes conhecimentos [tradicionais] e, nesse caso, seu impacto benéfico sobre a biodiversidade e, de outro lado, o problema das políticas públicas que atrapalham mais do que ajudam.

Mauro - Eu acho que um exemplo do efeito da política sobre como lidar com essa multiplicidade é o assunto sobre o qual eu estava escrevendo esses dias, que é o problema da crise ambiental, abordado por Eduardo Viveiros de Castro e a Débora Danowski ${ }^{65}$, e também por Latour. Latour estava no centro da famosa "guerra das ciências", em que Sokal ${ }^{66}$ submeteu a uma revista de humanidades uma paródia de "pós-modernismo", aceita pela revista. Sokal revelou a paródia, visando desacreditar a visão das humanidades sobre a ciência. Na época, tinha importância. A contratação de Latour para o MIT - para dar aulas de filosofia da ciência - foi vetada de cima. A argumentação meio bolsonarista era que, depois que o capitalismo derrotou o comunismo, depois do muro de Berlim, a nova frente do comunismo seria a destruição de uma base do capitalismo, que é a ciência. Então pessoas como o Latour representavam uma espécie de quinta coluna, que atacava a sociedade americana procurando deslegitimar a autoridade da ciência.

Manuela - Mauro, eu acho que você está querendo chegar, só pra dar um curto-circuito aí, em algo que é o seguinte: é que mudou a atitude do Latour.

Mauro - Mudou completamente. Você está vendo a revista aqui, Science, e a Nature, na minha mesa... E leio uma página inteira da Science dedicada ao Latour, em que Latour dá uma entrevista onde reafirma o consenso científico sobre o aquecimento global. Ele está dizendo que é preciso unir forças, fazer uma coalisão por Gaia, abrangendo cientistas, humanistas e povos do mundo. O livro da Débora Danowski e Eduardo Viveiros de Castro tem a mesma atitude. $O$ aquecimento global é tomado como um dado que é a posição do realismo científico, apoiado pelo consenso científico. Mas se você pensar no consenso da ciência, verá que não é uma ideia que requer uma intensa atividade de intermediação entre visões locais e a visão científica. Essa atividade de intermediação ontológica é dispensada porque se trata de uma guerra, uma guerra contra os que estão efetivamente destruindo povos indígenas, que estão destruindo a natureza no plano da percepção... Esqueçamos agora o realismo científico, porque os Yanomami ${ }^{67}$ veem esses efeitos, os Ashaninka ${ }^{68}$ veem isso, os ribeirinhos experimentam esses efeitos... O habitante, o biólogo, veem efeitos bem reais, são coisas bem reais. Não é uma mera discussão no nível filosófico, mas é uma discussão de engajamento. Eu acho que o engajamento se dá num plano pré-científico ou pré-filosófico.

Manuela - Atualmente estou participando de duas coalizões, quer dizer, eu estou na coalizão de ciência e sociedade, que são 72 cientistas, mas eu acho que sou a única cientista social ali, por uma série de circunstâncias, dentre as quais ter ajudado lá atrás no documento da SBPC sobre o código florestal. Acabei fazendo parte então desse grupo que atualmente é uma coalizão, liderada pela Mercedes Bustamante $^{69}$, que é uma ecóloga sensacional, tenho a maior admiração por ela. Ela é professora na UnB. E por isso, na semana passada, acabei fazendo um ras-
64 Diagnóstico povos indígenas e comunidades locais e tradicionais no Brasil: contribuições para a biodiversidade, ameaças e políticas públicas, que é um extenso material sobre estudos acerca das relações e efeitos de povos tradicionais sobre a biodiversidade.

65 Débora Danowyski, do Departamento de Filosofia da PUC-Rio. Aqui se trata de uma referência ao livro Há um mundo por vir?, de Débora Danowyski e Eduardo Viveiros de Castro, publicado pela Cultura e Barbárie, 2017.

66 Alan David Sokal, matemático da University College London.

67 Etnônimo que se refere a conjunto de subgrupos que habitam a fronteira Brasil-Venezuela na região do interflúvio Orinoco - Amazonas.

68 Grupo de língua Pano que habita a fronteira entre Brasil e Peru.

69 Mercedes Maria da Cunha Bustamante, ecóloga e professora da UnB. 
cunho de uma posição da coalizão sobre a questão de mineração e garimpo em área indígena. $\mathrm{O}$ Carlos Nobre ${ }^{70}$ me escreveu no dia seguinte dizendo que estava bom e que ele usaria numa coletiva de imprensa que ele ia dar a propósito do lançamento do documento final do Sínodo da Amazônia. São coisas diretamente políticas. Por outro lado, eu também faço parte da comissão de direitos humanos Dom Paulo Evaristo Arns, que foi fundada há um ano exatamente. É uma comissão composta por 22 pessoas, um grupo muito pequenininho, mas que tem um monte de ex-ministros - tanto do PSDB quanto do PT - com acesso a vários jornais e a um círculo político importante. Ali, também, o que a gente faz é analisar. Cada um tem uma espécie de relatoria. A que eu participo tem a ver com a questão indígena e todos os dias tem alguma coisa... Agora em março estamos promovendo, junto com o Instituto Socioambiental, um evento paralelo na reunião da comissão de direitos humanos da ONU, em Genebra, sobre o que está acontecendo com os povos indígenas isolados e recém-contatados. Então estamos fazendo toda uma movimentação, preparando documentos. Mas isso mostra que eu estou dando primazia a essas questões políticas. Por outro lado, a Academia Brasileira de Ciências me convidou, eu fiquei super-honrada, para fazer uma das conferências inaugurais da reunião este ano, e eu vou falar evidentemente de conhecimento tradicional e biodiversidade, e aí eu tenho de adotar um outro tom.

Joana - Manuela, quais são os maiores desafios que você enfrenta nesses trabalhos de atuação política, que você enumeraria nesse entrecruzamento de regimes de conhecimentos tão distintos?

Manuela - Deixa eu falar uma coisa, deixa eu dar um outro dado que talvez ajude porque que eu estou pensando ao mesmo tempo. Quando eu fiz aquela proposta pro Ministério de Ciência e Tecnologia, o que eu estava propondo era o seguinte: por um lado, o programa de apoio à colaboração entre cientistas e povos indígenas em temas mutuamente acordados, e por outro lado, um programa de apoio aos sistemas tradicionais de conhecimentos. São duas coisas separadas, porque eu acho que as duas coisas são importantes e o que eles me pediram para fazer foi estruturar as bases dessa proposta. E agora essa segunda parte é esse diagnóstico e o relato das experiências. Uma das experiências muito interessante foi liderada pelo Carlos Fausto ${ }^{71}$, com os Kuikuro, junto com Maira Smith ${ }^{72}$, de áreas das ciências naturais. É exatamente o tipo de colaboração que eu acho que é importante pôr em evidência e que eu gostaria de estimular. Por outro lado, estimular também a questão da continuidade dos sistemas tradicionais. Um dos problemas, dos nós, apontados no diagnóstico, está na segunda parte dele, que é sobre as políticas públicas, como as políticas educacionais e todos os quiproquós que vem daí. Uma coisa é evidente: as escolas enfrentam conflitos que prejudicam o aprendizado dos conhecimentos tradicionais.

Mauro - Mas eu queria, Manuela, complementar. Quero mencionar a etnografia da matemática exemplificada por Terezinha Nunes ${ }^{73}$ com vendedoras de coco em Feira de Santana, que mostrou que meninas vendedoras de coco faziam operações aritméticas na feira mas não conseguiam fazer as mesmas operações na escola $^{74}$. Tem muitos caminhos para a matemática, e há uma certo desprezo desse
70 Físico do INPE, e referência nos estudos sobre aquecimento global.

71 Antropólogo, professor do Museu Nacional/UFRJ.

72 Bióloga, trabalha no Conselho de Gestão do Patrimônio Genético do Ministério do Meio Ambiente. Veja o artigo: Socialidade e diversidade de pequis (Caryocar brasiliense, Caryocaraceae) entre os Kuikuro do alto rio Xingu (Brasil). Boletim do Museu Paraense Emilio Goeldi, v. 11, n. 1, p. 87-113, 2016.

73 Professora da University of Oxford/Inglaterra. 
lado prático e da experiência. Mas isso é só um exemplo de coisas que acontecem nesse ensino muito dogmático.

Enfatizo a colaboração e complementaridade entre conhecimentos tradicionais e a ciência de laboratórios. Laboratórios aceleram a pesquisa de possibilidades moleculares - mas resta selecionar as que são aplicáveis. E isso leva ao papel da experiência de comunidades indígenas e tradicionais para selecionar aplicações. Há então duas estratégias que podem ser complementares. Uma estratégia é dirigida a uma meta explorada em laboratório: obter variedades de mandioca com alto teor de betacaroteno, e em seguida convencer agricultores a adotar essa variedade. Outra via é permitir uma multiplicidade de experimentos por agricultores tradicionais, sem uma meta pré-determinada, que produzem variedades sob critérios múltiplos que podem ser vistos como aleatórios - com um laboratório que checa os resultados aleatórios por suas eventuais utilidades. Um exemplo muito interessante dessa segunda estratégia foi a descoberta de uma variedade de cassava com a propriedade de ser conservada fora da terra sem apodrecer durante muito tempo. Essa propriedade não foi antecipada nem buscada - mas foi descoberta "por acaso" em um almoxarifado no centro peruano de pesquisa de mandioca. E virou a manchete do ano no centro. A lição é que procedimentos de pesquisa estocástica e em paralelo podem levar a resultados importantes imprevistos pelo método determinístico e orientado para um fim pré-determinado. E esse método em paralelo e estocástico é a imagem da atividade de pesquisa de comunidades tradicionais. Sobre isso Manuela pode falar mais.
74 CARRATHER, Terezinha N.; CARRAHER, David William; SCHLIEMANN, Analucia Dias. Mathematics in the streets and in schools. British Journal of Developmental Psychology, v. 3, n. 1, p. 21-29, mar. 1985.

Manuela - Depois eu conto, agora vamos almoçar, vem! 